\title{
Non-destructive technique for individualizing trace evidence analysis of tiger nail
}

\author{
Ashvinkumar H. Italiya, Niha Ansari and Shobhana K. Menon* \\ Department of Forensic Science, School of Sciences, Gujarat University, Ahmedabad-380009, Gujarat, India
}

\begin{abstract}
Tigers are on the brink of extinction. The greatest threat comes from criminals who control an illegal trade spanning countries and continents. Those animals are illegally killed or poached owing to the high value of their fleece on the black market, and their body parts are used in traditional medicines and jewellery articles. The illegal trade in tiger and lion are one of the most high profile, destructive and urgent forms of wildlife crime. The enforcement response needs to employ advanced, intelligence-led methods of investigation and the engagement of the whole criminal justice system. The response must target the individuals who control this lucrative trade and bring them to justice, and also seize any assets obtained through their crimes. Tiger nail evidence as one of such criteria can provide important information for crime investigation. The present study deals with the new non-destructive technique namely FTIR-ATR (Fourier transform infrared spectroscopy- Attenuated total reflection) and VSC (video spectral comparator) analysis of the Royal Bengal Tiger claw (nail) applied for the first time in wildlife crime investigation especially in a forensic context.
\end{abstract}

\section{Introduction}

Wild tiger existence in the complete globe is only available to 13 countries $[1,2]$. Tiger inhabitants have noticeably decreased due to illegal consumption and commercialization of their body parts. In such cases hair, nail and bones samples are the only evidence found in the crime scene. Thus, they play an important role in species identification for wildlife forensic investigation. It is well known that tiger are known not only for their aesthetic beauty but also for their medicinal value in several countries. In 2007, environmental photojournalist Debby $\mathrm{Ng}$ who was worked with TRAFFIC, WWF, WSPA, and EIA, wrote in one of the reputed bulletin called Asia Magazine that both leopards and lions are now used as common substitutes for tiger bones. Yet with economic values of tiger bones, tigers are hunted which made need to monitor the number. With alternative approaches and new tools it possible to monitor tigers in Indian tiger reserve area [3]. It's a fact that animals have different nail pattern that can be detected and measured. An advantage of analyzing nail samples is easy and noninvasive collection, small sample size required and easy to storage at room temperature for longer time $[4,5]$.

Close inspection of the evolutionary "ladder" shows that nails are evolved from claws. The lowest evolutionary stage at which claws are present is in amphibian (Biedermann, 1926). Claws and their relatives (nails and hooves) are basically localized growths of hard keratin in the epidermis. The claw plate consists of hard keratin and corresponds to the stratum corneum of the epidermis. Beneath the exposed claw plate is the non-proliferative claw bed over which the newly formed nail moves distally (towards the distal end). In higher primates and man, nails have developed in conjunction with the acquisition of manual dexterity; other mammals do not possess such flattened claws. Histochemical methods shown that cystine, containing stable disulphide bonds, is concentrated particularly in the intermediate nail plate at the periphery of individual cells; the lowest concentration is found in the dorsal plate [3-8]. The reverse position applies with regards to bound sulphydryl groups, the highest concentration being present in the dorsal nail plate. Total sulphur concentration is similar in the dorsal and intermediate plates [9].

In this present study, nail samples of tigers was analyzed. Generally forensic scientists prefer using nondestructive methods of analyzing nail presented as trace evidences rather than using destructive methods. FT-IR (ATR) spectroscopy is a vibrational spectroscopic technique used for the nondestructive identification of molecular species, including synthetic fibers. Nail can be easily classified according to their chemical structures [10-12]. FT-IR (ATR) spectra provide the band assignments for the characteristic modes of vibration of keratin proteins in the FTIR spectral region between $1750-750 \mathrm{~cm}^{-1}$. This region is often referred to as the "fingerprint region" of the keratin fiber mainly because it contains the major amide bands, $\mathrm{CH}$ deformations cysteine oxides. The first amide band is referred to as amide I and represents primarily the $\mathrm{C}=\mathrm{O}$ stretching vibration coupled to the in-plane bending of the $\mathrm{N}-\mathrm{H}$ and stretching of $\mathrm{C}-\mathrm{N}$ bonds same as amide II \& amide III respectively $[13,14]$.

Few species of tigers are left in the world and we have observed that tigers have species specific nail pattern. So, in current study, the set up was made to develop nail identification library using advanced tools which will be encase to develop tiger tracing element and ultimately in generating effective governance and rules, and improve the quality of criminal justice responses to wildlife crime.

Correspondence to: Shobhana K. Menon, Department of Forensic Science, School of Sciences, Gujarat University, Ahmedabad, -380009, Gujarat, India, Tel: 079-26300435 3; E-mail: shobhanamenon07@gmail.com

Key words: Wildlife investigation, tiger nail, FT-IR (ATR) spectroscopy, VSC$6000 \mathrm{H} / \mathrm{S}$

Received: March 10, 2017; Accepted: April 05, 2017; Published: April 08, 2017 


\section{Materials and methods}

\section{Collection and sample preparation}

The study involves the tiger nail as the investigation sample. The target was focused to tiger nail as standard as these samples were not subjected to any poacher. The total of 36 nails, 18 each from male and female tiger was analyzed. The samples were collected from Sakkarbaug Zoo, Junagadh. These nails were first subjected to a clear wash of laboratory reagent grade acetone and were then examined as traditional point of view for its color, shape, size and texture. Further microscopic examination includes the observation of pigmentation and scale patterns.

\section{Microscopic examination}

Samples were examined under microscope (Lieca CFM-2) at 40X and 100X for its color, pigmentation and scale. The nail surface was analyzed with the unaided eye to determine possible difference in color depending on which side is viewed. The nail surface was examined with a compound microscope using transmitted light (Leica CFM2, 40X-100X, Leica Microsystems, Wetzlar, Germany) in order to determine outer layer structure.

\section{FT-IR (ATR) spectroscopy analysis}

FT-IR (ATR) spectroscopy was used to evaluate the composition of nails. ATR was chosen because it is primarily a surface technique in that the depth of analysis is approximately 2 micrometers (Merrill and Bartick 2000). If any animal's nail was similar, then the ATR data is considered conclusive with regard to structure identification. The infrared spectrometer was Alpha-FT-IR ESP (Enhanced Synchronization Protocol) equipped with a $\mathrm{KBr}$ beam splitter and a DTGS detector.

The ATR accessory was a Bruker IR Technologies (Danbury, Connecticut) and a resolution of $8 \mathrm{~cm}^{-1}$ with a $\mathrm{ZnSe}$ crystal. Known and unknown sample spectra and background scans were taken in transmittance mode with a spectral range of 2000-500 $\mathrm{cm}^{-1}[11,14-19]$ and a curve fit analysis was studied.

\section{Chemometric analysis}

The problem of handling large amounts of data for purposes such as learning, recognition and prediction, requires the application of special techniques known as chemometrics techniques. The double centered matrices as obtained from peak of curve fit analysis were imported into the commercially available software package for multivariate analysis and experimental design, Unscramble X version 10.3.0.89 (C) Copyright, Pattern Recognition Systems CAMO Software, 2009-2013). These matrices were then processed to produce the resultant PCA scores-scores plots [35].

\section{$\underline{\text { Results and discussion }}$}

\section{Natural characteristics identification- tiger (Panthera tigris)}

The natural characteristics of identification of tiger (Panthera tigris) nail shows dark blond color with rough surface having hollow cavity and root portion is uniformly open and a larger cavity. The tip point is broad and elliptical with absence of outer circle ring (Table 1).

\section{Microscopic examination}

The nail surface was analysed with the unaided eye to determine possible difference in color depending on which side is viewed. The
Table 1. Natural characteristics identification

\begin{tabular}{|c|c|}
\hline Character & Observation \\
\hline Color & Dark blond \\
\hline Surface & Rough \\
\hline Curve & Medium Curvature \\
\hline Circle ring & Outer circle ring Absent \\
\hline Thickness & Broad \\
\hline Tip point & Broad and High Elliptical \\
\hline Hollow cavity & Present \\
\hline Root portion & Open and Uniform \\
\hline Root Cavity & Large open \\
\hline
\end{tabular}

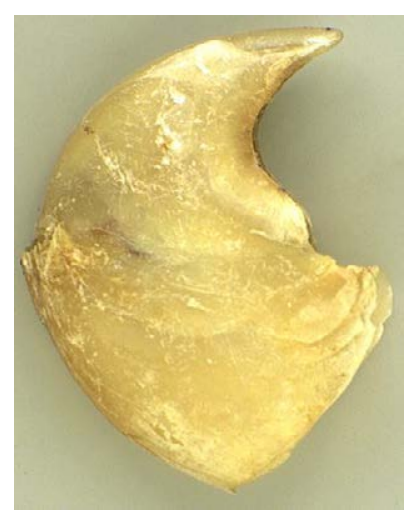

Figure 1. Shows original tiger nail sample.

Table 2. Microscopic observation.

\begin{tabular}{|c|c|}
\hline Character & Observation \\
\hline Color & Medium Golden Brown \\
\hline Pigmentation from Tip to root & Dense in Complete nail \\
\hline Hollow Cavity & Near to tip \\
\hline Scale & Diamond Petal \\
\hline
\end{tabular}

nail surface with a compound microscope (Figure 1) using transmitted light shows results as in Table 2 in order to determine outer layer structure (Table 2).

\section{FT-IR ATR spectrum}

The FTIR (ATR) spectra of all the 36 nail samples were scanned in the spectral range $2000-500 \mathrm{~cm}^{-1}$ [33-34]. In the sample No.6 peak at $1514 \mathrm{~cm}^{-1}$ shifted from $1517 \mathrm{~cm}^{-1}$, sample no. 1 to 5,7 to 12,14 to 21 are common peak and slightly different in $1514 \mathrm{~cm}^{-1}$ pick depth, sample 8 no.13, 22 and 32 peak at 1037 and 1741 are slightly shifted peak the variation was $\pm 1.52 \mathrm{~cm}^{-1}$ from this spectra and sample no.23-31 and $33-36$ the intensity of peak depth are $\pm 10 \%$ was found (Figure 2 ). The reasons are due to the stretching frequency, intensity, concentration of amino acid and other metallic compound composition.

Table 3 shows the major vibrational band assignments of tiger nail keratin and Table 4 shows amide and cysteine bond vibration (Table 3 and 4$)$.

\section{Curve-fit analysis of FT-IR spectra}

The spectral (or "fingerprint") region between $2000-500 \mathrm{~cm}^{-1}$ was curve fitted into the molecular bases for the discrimination observed by Chemometrics [11,14-16]. The region contains bands such as amide-I, II, III, CH2, CH3, deformation and cysteic acid vibrations. Overall bands were curve fitted and the results were presented. Table 5 shows backbone and sulfur bond present in tiger nail. 


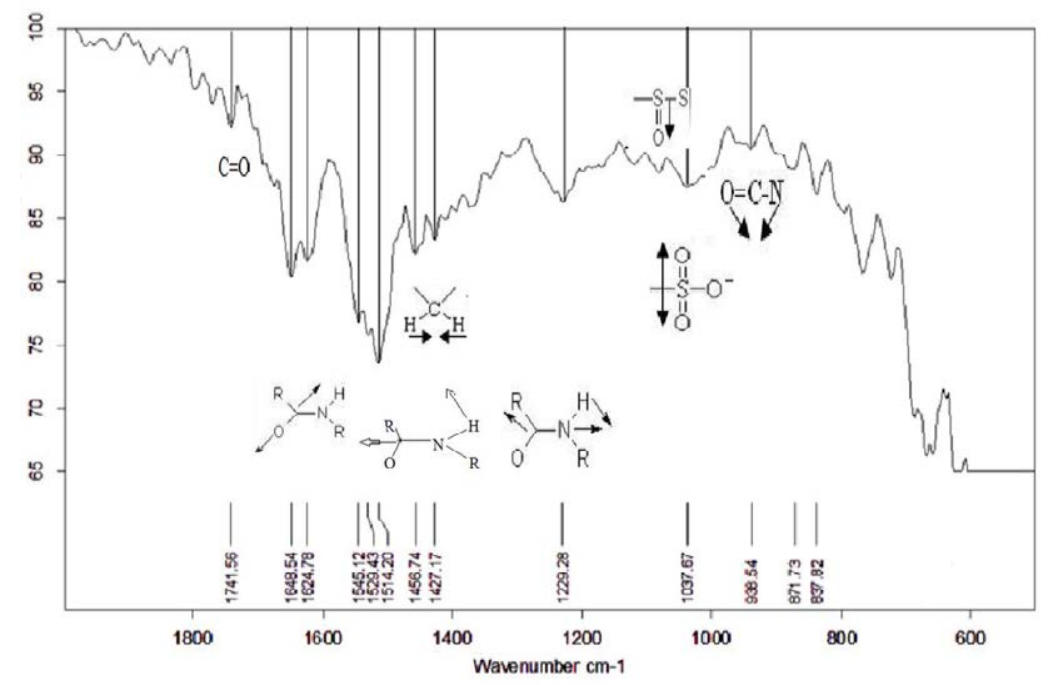

Figure 2. Shows FT-IR ATR spectrum of nail from a Panthera Tiger after cleaning of the surface.

Table 3. Major vibrational band assignments of tiger nail keratin.

\begin{tabular}{|l|l|}
\hline Group & Range $\left.\mathbf{( c m}^{-1}\right)$ \\
\hline O-C-N (O and N Stretching) & $938 \pm 1.83$ \\
\hline -SO-3 Cystic Acid Stretch(O Bond Stretching) & $1037 \pm 1.05$ \\
\hline Amide - III C-N (Vibrations) & $1229 \pm 1.17$ \\
\hline H-C-H (Stretching) & $1427 \pm 1.25$ \\
\hline$\delta$ C-H (Deformation band) & $1456 \pm 1.32$ \\
\hline $\begin{array}{l}\text { Amide-II: } 60 \% \text { C-N stretch 40\% N-H in plane band Minor } \\
\text { Contributions C-C, N-C stretch, C=O in plane ban }\end{array}$ & $1624 \pm 1.31$ \\
\hline Amide-I: $80 \%$ C $=$ O stretch, C-N stretch, C-CN & $1648 \pm 1.73$ \\
\hline Amide-I: C=O ( $\alpha$ helix) & $1741 \pm 1.56$ \\
\hline C=O (Stretch) & $837 \pm 1.41$ \\
\hline O-H (Stretch) tyrosine (Phenolic) & \\
\hline
\end{tabular}

Table 4. Amide and cysteine bond.

\begin{tabular}{|l|l|}
\hline Group & FT-IR Vibrations $(\mathbf{c m}-1)$ \\
\hline Amide-I & $\begin{array}{l}\mathrm{C}=\mathrm{O}(\alpha \text { helix }-1648) \pm 1.73 \\
\mathrm{C}=\mathrm{O}(\beta \text { Plated sheet }-1624) \pm 1.31\end{array}$ \\
\hline Amide-II & $\begin{array}{l}\delta(\mathrm{N}-\mathrm{H}), \mathrm{C}-\mathrm{N}(\alpha \text { helix }-1545) \pm 1.02 \\
\delta(\mathrm{N}-\mathrm{H}), \mathrm{C}-\mathrm{N}(\beta \text { Plated sheet }-1529,1514) 1.02, \pm 1.10\end{array}$ \\
\hline Amide-III & $(\mathrm{C}-\mathrm{N}), \delta(\mathrm{N}-\mathrm{H})$ Random coiled $-1229 \pm 1.17$ \\
\hline $\boldsymbol{\delta}(\mathbf{C H} 2)(\mathbf{C H} 3)$ & $1456 \pm 1.32$ \\
\hline Cysteine Oxidase & $(\mathrm{S}-\mathrm{O})$ Cysteic acid1037 \pm 1.05 \\
\hline
\end{tabular}

Table 5. Backbone and sulfur bond present in tiger nail.

\begin{tabular}{|l|l|}
\hline Structure & FTIR Vibrations $[\mathbf{C m}-1]$ \\
\hline Peptide backbone structure & $\begin{array}{l}\text { Amide I, II and III }(\alpha \text { Helix 1624, } \beta \text { Sheet 1648; } \\
\alpha \text { Helix 1514, } \beta \text { Sheet 1545; } \beta \text { Sheet 1229) }\end{array}$ \\
\hline C-C Skeletal backbone & 1456 \\
\hline C-C, S-S, C-C Sulfur containing group & 1037,524 \\
\hline
\end{tabular}

The bands representing keratine can be seen at amide- $\mathrm{C}=\mathrm{O}(\alpha$ helix - 1648), $\mathrm{C}=\mathrm{O}(\beta 1$ Plated sheet - 1624), Amide-II $\delta(\mathrm{N}-\mathrm{H}), \mathrm{C}-\mathrm{N}$ ( $\alpha$ helix - 1545), $\delta(\mathrm{N}-\mathrm{H}), \mathrm{C}-\mathrm{N}$ ( $\beta$ Plated sheet - 2 1529,1514) Amide-III $(\mathrm{C}-\mathrm{N}), \delta(\mathrm{N}-\mathrm{H})$ Random coiled - 1229. $\delta(\mathrm{CH} 2)(\mathrm{CH} 3)$ 1456, cysteine oxidase (S-O) cysteic acid 1037 (15-19) (Figure 2).

Curve-fit of the relative intensity area of the cysteic acid band (1037 $\left.\mathrm{cm}^{-1}\right)$ is indicated. The frequencies of the amides are sensitive to peptide conformation and hydrogen bonding can be used to characterize the secondary structure of the peptide backbone. Analysis of the relevant intensity area of amide-I ( $\alpha$ Helix 1624 and $\beta$ Sheet1648), amide-II ( $\alpha$ Helix 1514 and $\beta$ Sheet 1545$)$ and amide-III $\left(1229 \mathrm{~cm}^{-1}\right)$ indicates secondary structure of the FT-IR ATR Spectra of the tiger nails. In addition, the intensity of band at $1456 \mathrm{~cm}^{-1}, 1427 \mathrm{~cm}^{-1}$ corresponds to $\mathrm{CH} 2, \mathrm{CH} 3$ Vibrations respectively [19-27].

In the preferred $1690-1500 \mathrm{~cm}^{-1}$ region, conformational changes keratin protein attributed to the $\alpha$-helical to $\beta$-sheet transitions in the amide I and amide II vibrations played a significant role in matching and discrimination of the spectra and hence, the claw samples [11,23-32].

FT-IR (ATR) spectroscopy had two important advantages over to the previous methods: (i) sample throughput and spectral collection were significantly improved (no physical flattening or microscope manipulations), and (ii) given the recent advances in FTIR (ATR) instrument portability, there is real potential to transfer this work's findings seamlessly to on-field applications. In terms of the investigation's novel contribution to the field of forensic science, it has allowed for the development of a novel, multifaceted, methodical protocol where previously none had existed. The range of FT-IR from $1750 \mathrm{~cm}^{-1}$ to $700 \mathrm{~cm}^{-1}$ is the most important region for the identification of keratin protein. The protocol is a systematic method to rapidly investigate unknown or questioned single tiger nail FTIR-ATR spectra from different animal and species, including nail of different synthetic materials. It is based on the FTIR-ATR results that there is no variation in the secondary structure in the nail keratin even on the bases of the gender variable.

\section{Chemometric analysis}

The matrices were processed to produce the resultant PCA (Principal Component Analysis) scores-scores plots. Initially, when the entire spectral database was processed, the PCA PC1 vs. PC2 scores-scores plot for the $1750-800 \mathrm{~cm}^{-1}$ wave number region appeared complex. This plot showed that there were significant atypical spectra present from specific individuals. These objects influenced the core group to cluster heavily around the origin (Figure 3).

The PC1 loadings plot for the $1690-1500 \mathrm{~cm}^{-1}$ region (Figure 3) is also similar to the loadings analysis of the original tiger nail spectra. The original and fake nails are influenced by the $\alpha$-helical and $\beta$-pleated sheet of the amide I and amide II bands (black) between 1660-1600 


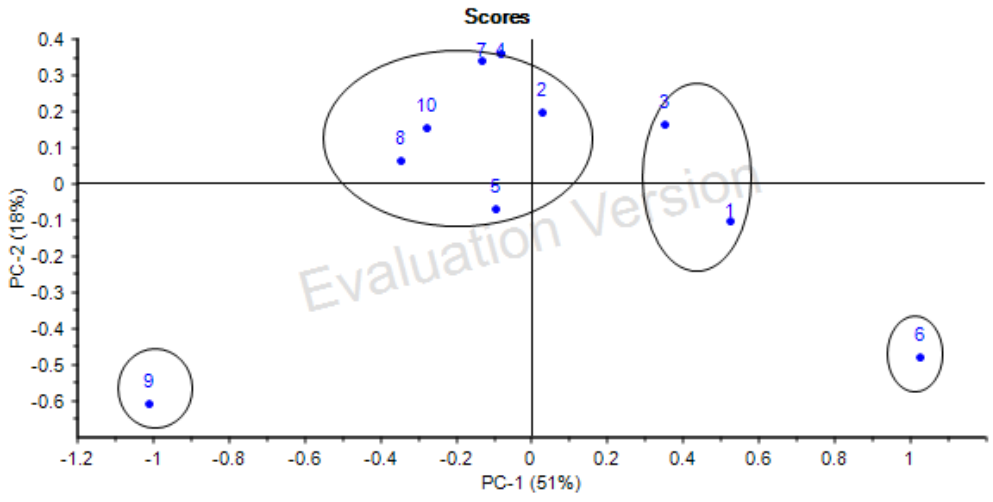

Figure 3. Indicating PC1(51\%) vs. PC2 (18\%) scores plot of original tiger nails main component for the royal Bengal tiger between $1750-800 \mathrm{~cm}^{-1}$.

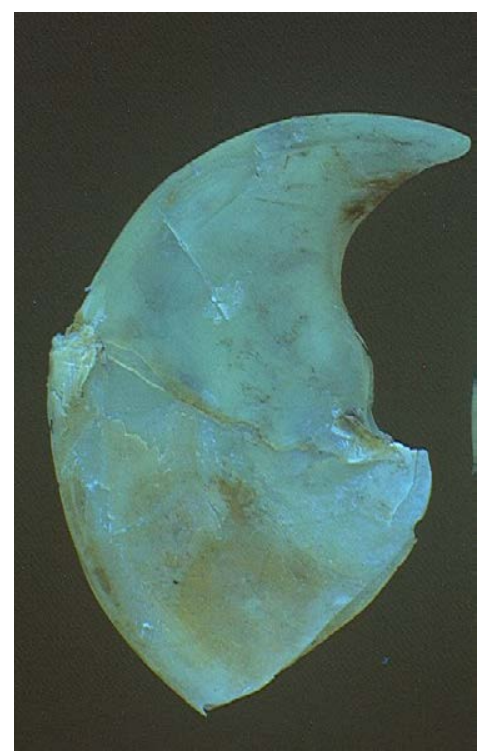

Figure 4. Tiger nail showing cadet blue fluorescence under VSC 6000/HS foster freeman.

$\mathrm{cm}^{-1}$ and $1550-1500 \mathrm{~cm}^{-1}$ respectively. Conversely, the fake nails are influenced by the changes occurring to the amide $\mathrm{I} v(\mathrm{CONH} 2)$ stretch of the asparagine and glutamine side chains and $v(C=O)$ stretch of the $\beta$-pleated sheet and random coil conformation between approximately $1690-1670 \mathrm{~cm}^{-1}$; the anti-symmetric va $(\mathrm{C}=\mathrm{O})$ carbonyl stretch of aspartic and glutamic acid between $1590-1570 \mathrm{~cm}^{-1}$ (green); and the vibration of the tri-substituted indole ring of tryptophan between 1570 $1550 \mathrm{~cm}^{-1}$. Hence, the pattern of loadings bands of the Royal Bengal Tiger claws spectral objects are similar to those from the African and other genus as per the proposed forensic protocol $\left(1750-800 \mathrm{~cm}^{-1}\right)$ and the alternate region $\left(1690-1500 \mathrm{~cm}^{-1}\right)[19,20,24]$.

\section{Fluorescence detection under video spectral comparator}

The tiger nails were checked with VSC for using short, medium and long wave length UV source and it was found that under all these condition tiger nails exhibited cadet blue fluorescence this can be used for the identification. Only genuine nails exhibit cadet blue fluorescence under UV- light (Figure 4).

Therefore, to obtain a more reliable identification of tiger nail, a combination of the main characteristics showing low intra-species variations and other characteristics showing high interspecies variations is recommended. The establishment of a database that contains nail morphological characteristics and their variations of commonly traded or endangered species would be ideal. All these will lead to increased confidence in using nail morphology in species identification and will be beneficial for wildlife forensic investigation.

\section{Conclusion}

The results presented have provided an alternative approach to the characterization of single portion of the tiger nail, which is rapid, easy to operate and provides objective results that can be readily produced and explained in the court of law with reliability. The rapid detection and analysis of results have not previously been possible with the lengthy and quite laborious microscopic comparison techniques and DNA analysis. The study in relevance to it has shown interpretations of each technique at molecular levels, for investigations. In case where control nails are not readily available or incase where the unknown sample cannot be matched to either nail from the particular animal or suspect animal, it is then possible, through FT-IR microscopy to establish the characteristics of a nail. With such a database, it will be possible to use statistical methods to achieve classifications based on a combination of both quantitative and qualitative nail characteristics, which should help to assign probabilities using likelihood ratios in reporting forensic species identification.

\section{Acknowledgements}

One of the author's gratefully acknowledges UGC-New Delhi for Junior Research Fellowship. We are thankful to Dr. A. P. Singh, Chief Conservator of Forest, Junagadh for providing the samples for the research work and also for his guidance. We thank Bahaudin Science College, Junagadh for providing FT-IR (ATR) facility. Guidance from Mr. Kapilkumar Department of Forensic Science, Ahmedabad is gratefully acknowledged.

\section{References}

1. Bauer H, Nowell K, Packer C (2008) "Pantheraleo" International Union for Conservation of 12 Nature. Version 2010:2.

2. CITES (Convention on International Trade in Endangered Species of Wild Fauna and Flora), 14 https://www.cites.org/, Joint Meeting of the Animals and Plants Committees, Shepherdstown 15 (United States of America) 2000.

3. Johnsingh AJT, Madhusudan MD (2009) Reintroduction of Top-Order Predators, 17 Blackwell Publishing Ltd.

4. Bryant HN, Russell AP, Laroiya R, Powell GL (1996) Claw retraction and protraction in the Carnivora: skeletal microvariation in the phalanges of the Felidae. $J$ Morphol 229: 289-308.[Crossref]

5. Bininda- Emonds ORP, Gittlema JL, Purvis A (1999) Building large trees by combining 22 phylogenetic information. A complete phylogeny of the extant carnivore 
(mammalia), Boil, 23 Rev. 74: 143-175

6. Gupchup GV, Zatz JL (1999) Structural characteristics and permeability properties of 25 the human nail: A review. J Cosmet Sci 50: 363-385.

7. McGowan KM, Coulombe PA (2000) Keratin 17 expression in the hard epithelial context of the hair and nail, and its relevance for the pachyonychia congenita phenotype. J Invest Dermatol 114: 1101-1107.[Crossref]

8. Martin LD (1980) Fuctional morphology and the evolution of cats. Trans Nebraska Acad Sci 8: 141-154.

9. Fraser RDB, MacRae TP, Rogers GE (1972) Keratins: Their Composition, Structure and Biosinthesis. Charles C Thomas, U.S.A.

10. Tu AT (1982) Raman Spectroscopy in Biology: Principles and Applications. John Wiley and Sons, U.S.A

11. Baddiel CB (1968) Structure and reactions of human hair keratin: an analysis by infrared spectroscopy. J Mol Biol 38: 181-199.[Crossref]

12. Miller JV, Bartick EG (2001) Forensic analysis of single fibers by Raman spectroscopy. Appl Spectrosc 55(12):1729-1732.

13. Szymanski HA, Erickson RE (1970) Infrared Band Handbook. Plenum Press, New York, Volumes 1970.

14. Hollas JM (1996) Modern Spectroscopy, 3rd edition. John Wiley \& Sons, New York.

15. Coates JP (1996) ‘The Interpretation of Infrared Spectra: Published Reference Sources'. Appl Spectrosc Rev 31(1-2): 179-192.

16. Bellamy LJ (1975) Infrared Spectra of Complex Molecules. Chapman \& Hall, New York, Vol. 1. 19

17. Bellamy LJ (1980) Advances in Infrared Group Frequencies, Infrared Spectra of Complex Molecules. Chapman \& Hall, New York, Vol. 2.

18. Colthrup NB, Daly LH, Wiberley SE (1990) Introduction to Infrared and Raman Spectroscopy. 23 Academic Press, San Diego, CA.

19. Socrates G (1994) Infrared Characteristic Group Frequencies. John Wiley \& Sons, New York.
20. Lin-Vien D, Colthup NB, Fateley WG, Grasselli JG (1991) Infrared and Raman Characteristic 27 Frequencies of Organic Molecules, Academic Press, San Diego, CA.

21. Smith B (1999) Infrared Spectral Interpretation, a Systematic Approach. CRC Press, Boca Raton, FL.

22. Nakamoto K (1997) Infrared and Raman Spectra of Inorganic and Coordination Compounds. Parts A and B, John Wiley \& Sons, New York.

23. Nyquist RA, Putzig CL, Leugers MA (1997) Handbook of Infrared and Raman Spectra of Inorganic Compounds and Organic Salts. Academic Press, San Diego, CA.

24. Haslam J, Willis HA, Squirrel DC (1972) Identification and Analysis of Plastics. John Wiley \& Sons, New York, 1979; originally published by Iliffe. London.

25. Hummel DO, Scholl FK (1980) Atlas of Polymer and Plastics Analysis VerlagChemie, Weinheim. Vol. 1-3:1980-81.

26. Koenig JL (1992) Spectroscopy of Polymers. American Chemical Society, Washington, $\mathrm{DC}$

27. Coates JP (1996) 'Questions and Answers: What to Do When the Sample Arrives, Part II’. Spectroscopy. 11(5):24-32.

28. Coates JP (1996) 'Into the Unknown: the First in the Series'. Spectroscopy. 11(5): 32-39.

29. Coates JP (1996) ‘Once More into the Unknown’. Spectroscopy 11(6): 14-23.

30. Coates JP (1998) 'A Review of Sampling Methods for Infrared Spectroscopy'. Academic Press, New York.49-91.

31. Coleman PB (1993) Practical Sampling Techniques for Infrared Analysis. In: CRC Press, Boca Raton FL (Ed.)

32. Dent G, Chalmers JM (1997) Industrial Analysis with Vibrational Spectroscopy. Royal Society of Chemistry, Cambridge.

33. Togkalidou T, Fujiwara M, Patel S, Braatz RD (2001) Solute concentration prediction using chemometrics and ATR-FTIR spectroscopy. 231(4): 534-543.

34. Gershevitz O, Sukenik CN (2004) In situ FTIR-ATR analysis and titration of carboxylic acid-terminated SAMs. J Am Chem Soc 126: 482-483.[Crossref]

Copyright: (C2017 Italiyaa AH. This is an open-access article distributed under the terms of the Creative Commons Attribution License, which permits unrestricted use, distribution, and reproduction in any medium, provided the original author and source are credited. 